\title{
Urban Analysis and Smart Communities: An Approach to the Use of Technology in Everyday Mobility*
}

\section{Análisis Urbano y Comunidades Inteligentes: "Una Aproximación al Empleo de la Tecnología en la Movilidad Cotidiana"}

DOI:http://dx.doi.org/10.17981/ingecuc.11.1.2015.01

Review Article - Reception Date: August 19, 2014 - Acceptance Date: December 12, 2014

Zurisaddai de la Cruz Severiche Maury

Master in Telematics Engineering, Universidad de Vigo. Vigo (España). zurisaddai_sm@yahoo.com.mx

Ana Fernández Vilas

Doctor of Computer Science, Universidad de Vigo. Vigo (España). ana.Vilas@det.univigo.es

To cite this paper:

Z. C. Severiche Maury and A. Fernández Vilas, "Urban Analysis and Smart Communities: An Approach to the Use of Technology in Everyday Mobility”, INGE CUC, vol. 11, no. 1, pp. 9-24, 2015. DOI: http://dx.doi.org/10.17981/ingecuc.11.1.2015.01

\begin{abstract}
Concentration of population in urban centers is a global problem for which different strategies in order to organize different processes in cities and improve the quality of life are required. The creation of smart communities is shown as a sustainable solution since they deal with various key aspects, such as traffic management and mobility, through the use of information technologies (ITs). This work presents a review of recent studies using information technologies for urban analysis and mobility in cities. A descriptive analysis of automated methods for collecting and analyzing citizens' mobility patterns is performed; it is centered in smart card use, geolocation and geotagging. It is concluded that a robust communication infrastructure, supported by an efficient computational platform allowing big data management and ubiquitous computing, is a crucial aspect for urban management in a smart community.
\end{abstract}

Keywords-- Smart Community, Urban Analysis, Pattern Mobility, Smart Cards, Geolocation, Geotagging.
Resumen-- La concentración de la población en los centros urbanos es una problemática mundial que requiere de estrategias que permitan organizar sus procesos y mejorar la calidad de vida. La creación de comunidades inteligentes se muestra como una solución sostenible, debido a que éstas trabajan aspectos claves para el desarrollo urbano, como la gestión de tráfico y la movilidad, apoyada en las tecnologías de la información (TICs). Este trabajo presenta una revisión del estado del arte en cuanto a la aplicación de las TICs al análisis urbano y movilidad ciudadana. Se analizan descriptivamente diversos métodos automáticos para la recolección y el análisis del patrón de movilidad de los ciudadanos, enfocándose en el uso de tarjetas inteligentes, geolocalización y geoetiquetado. Se encuentra que una infraestructura de comunicaciones robusta, apoyada en una plataforma computacional ágil con manejo de grandes datos y computación ubicua, es primordial para la gestión urbana en una comunidad inteligente.

Palabras claves-- Comunidad Inteligente, Análisis Urbano, Gestión de Tráfico, Movilidad, Patrón de Movilidad, Tarjetas Inteligentes, Geolocalización y Geoetiquetado. 


\section{INTRODUCTION}

For the last decades, the growth of population density and its concentration in urban centers has become a great concern. Governments worldwide, especially from developed countries, are interested in formulating new strategies to organize different process within cities so as to accomplish major efficiency both in resource use and economic and social improvement [1]. Consequently, analysts have estimated that in a near future, more than half of the population will live in urban areas. According to the United Nations Population Fund -UNFPA, it is expected that cities' population in 2030 reach 5000 million people, i.e., $70 \%$ of the total population [1]. Fig.1 illustrates urban population growth from 1950 to 2030 [1].

In the same way, it can also be observed in Fig. 1 that cities from developing nations will host $80 \%$ of the urban population in the world, while developed countries will remain almost the same. The global concern is related to the consequences deriving from such conurbation: an increase in poverty rates, civil unrest, unplanned urban growth, and environmental damages. The most suitable solution involves a serious organization of cities.

To counteract this growing urbanization of the world's population, the creation of new communities that foster equality and harmonious coexistence is mandatory. In order to achieve this, current urban centers must become "more efficient, habitable, and sustainable places, both in the short and long run, through the participation of the city itself, its citizens, and companies." [2]

Based on the formerly mentioned facts, it can be said that innovative solutions for these problems are required with the intention of improving people's wellbeing and their productive capacity [2]. In- formation and Communication Technologies -ICTs play an important role in this process as their use allow the creation of organized smart cities (smart communities) in which every process and service influencing the quality of life of its inhabitants is technologically supported, thus, becoming sustainable and superefficient communities.

This work seeks to lay out the review of major research projects related to the improvement of diverse organization processes in cities, such as urban mobility through vanguard technology and comprehensive logistics development to make the concept of 'smart city' or 'smart community' a reality.

This paper is structured as follows: section III sets out the concept of smart communities; section IV focuses on management levels of smart communities; section $\mathrm{V}$ sets forth the progress regarding urban analysis and mobility; section VI states its applications; section VII, discussion; and finally, section VIII, poses the conclusions.

\section{Methodology}

The purpose of this paper is to help other urban and smart community researchers, especially in urban mobility matters. A literature review is offered based on the latest vanguard studies regarding this topic. For bibliography localization, several document database indexes and academic search engines like Google Scholar were used.

The review offers key aspects in this subject, classifies smart community management into levels, and identifies the different methods utilized to collect and analyze citizens' mobility patterns. Moreover, it includes applications for these mobility patterns aiming at studies concerning traffic management improvement and service location planning.

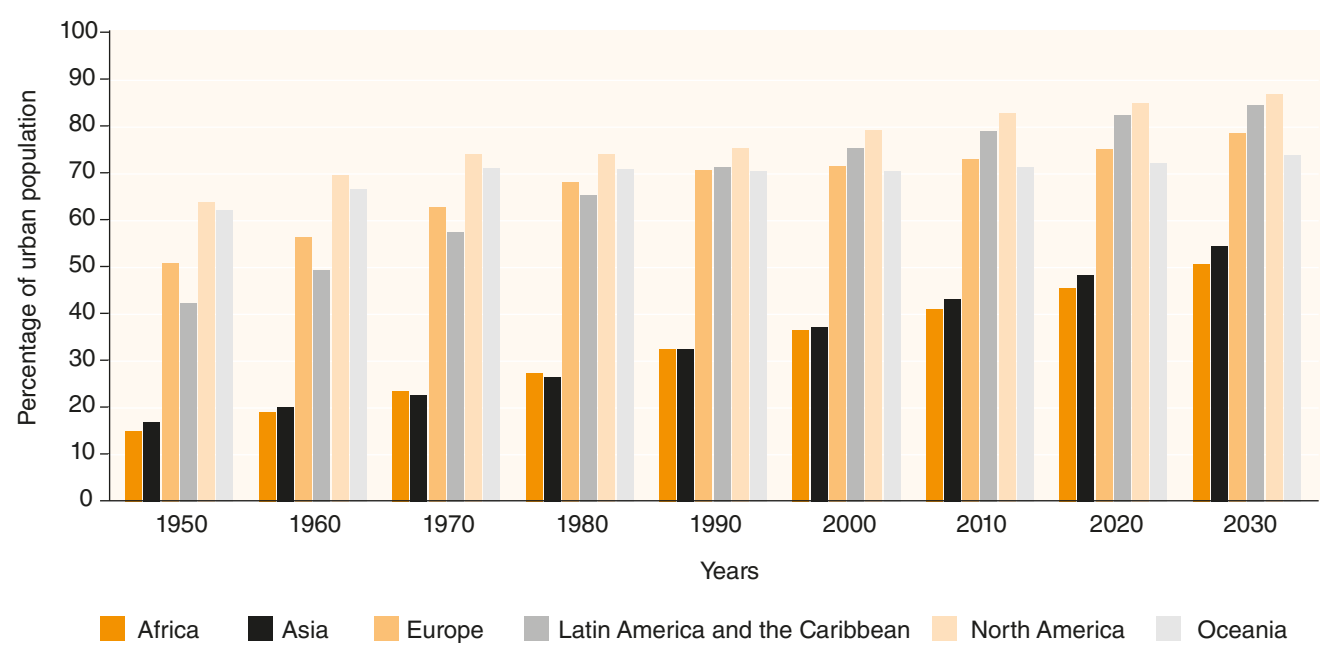

Fig. 1. Percentage of population residing in urban areas; 1950-2030. Source: UNFPA [1] 


\section{Smart Community Concept}

A community is a social unit whose members share a common interest that leads them to a daily interaction and to form associations among them, hence, developing numerous relationships and working towards a common benefit [3]. So, in a community, the fact of people sharing a common ethos -i.e., a common way of living- is fundamental. Likewise, other definition states that a community is a social group sharing a geographical area and, all or some of, the relationships that arise in this location [4]. Finally, in [5] a community is described as a group of people living in the same geographical area and sharing a common ethos. Nonetheless, all these definitions agree on the fact that a community is an area enclosing a great number of elements of a collective life, in this particular case, a group of people bound together by common interests focused on finding practical solutions to their problems. The pursuit of common welfare is a characteristic of all communities, and to achieve this, ICTs can serve as a control means for urban managing, social interaction, and physical urban environment aspects, hence, becoming smart or superefficient communities. According to the World Foundation for Smart Communities, a smart community consciously seeks solutions for their social and economic needs through technology with the purpose of transforming life and work within its area in a meaningful way. The singularity of these communities resides on the fact that, due to the nature of technology, the transformation process is vertiginous [6].

In a smart community, the wellbeing of its inhabitants is sought through the improvement of the physical environment and of the multiple processes involved in economic, politic, and social interaction [7]. In terms of the physical environment, a monitored setting is likely to be built using well-established and novel technologies like broadband communication links (wireless or through optical fiber), and wireless sensor networks for data exchange or the interconnection of habitants and the community's components. Such technology resources enable information to reach homes, schools, offices, hospitals, surveillance and emergency services, and cultural centers, among others, when opportune. All these resources combined with ubiquitous computing (ubicomp) systems grant service provision to everyone from almost any place with internet connection; thus, involving the community in the concept of the Internet of Things -IoT and allowing a simpler management of urban transportation, a faster access of the city's resources, localization availability, and a simpler public and private service provision, among other features [8]. In other words, it seeks an improvement of the physical environment through the systematization of homes and external settings, accessibility, energy and other resources conservation, safety, comfort, and health maintenance [9].
However, changes are not only expected for the physical milieu; interaction among community members in cities is also involved. These include political and social interactions among citizens, and between them and the Government. Easy information access, data processing platforms, social networks, and the interconnection of all urban structures grant this kind of interaction. In cities, social and physical setting technologies converge to improve inhabitants' daily lives [7].

Therefore, a smart community utilizes ICTs to transform the physical environment and human interactions within their action area [8]. Such transformation aims at improving the quality of life through the exploitation of ubicomp, thus, resulting in a ubiquitous 'intelligence' [9].

On the other hand, when speaking of the concept of community, it is generally thought of a large group living up-close, i.e., a group of people or organizations located within the same area. Nevertheless, the geographical area of a smart community varies in size -it can range from a neighborhood to a region; hence, a big city can be understood as a set of communities [10], [11], each with their own unique and distinguishing characteristics.

\section{Management Levels In Smart Communities}

A smart community is distinguished by different aspects or management levels like: urban management, traffic and mobility management, smart government, smart economy, communication infrastructure, environmental management, social management, human interaction systems, smart buildings, and big data analysis. These are described hereunder.

\section{A. Urban Management}

Through smart systems (sensor and actuator networks) and ICTs, its aim is to offer public services that improve both the urban setting and the quality of life. Within this feature, the following are included: urban furniture and public space design, real-time monitoring of public spaces, and planning of sustainable urban development (location and orientation of buildings, street planning, and vegetation use in urban designs) in order to take advantage of natural resources like solar energy, natural flow of winds, and the creation of adequate climatic conditions, among others.

At a technological level, a recurrent aspect present in urban management is public spaces monitoring through the use of Wireless Sensor Networks -WSN [12]. This use enables the collection of measurement data from the environments where it is installed for its later use. These WSN subsystems can be used for environmental measurements or real-time monitoring of objects. They can be installed in diverse locations to perform different tasks like parking assistance in public or private parking lots, structural 
monitoring of buildings, and garbage containers and highway monitoring, among others, depending on the specific application assigned [12].

Another example for public space monitoring is McKIZ Aware Community project, which was implemented to transform an elderly community into a space where they could perform their daily activities easily and improve their quality of life [13]. A peculiar aspect of this project is the fact that it considers the activities performed by this group of people in and out their homes, i.e., includes the public space. In order to do so, the systems and devices operated by the individuals are elements they can actually use in their routines or that are immersed in their day-today environments. In this manner, sensors and other technological systems in urban infrastructure, like streets, buses, stores and leisure spaces, are totally integrated into the community center [13]. Finally, this integration will result in a permanent monitoring of the public space and the individuals in it.

\section{B. Traffic and Mobility Management}

It comprehends the accomplishment of safety and efficiency in transportation systems through the implementation of smart technologies. Within this spectrum, features like transport infrastructure, accessibility, eco-friendly cars, traffic flow, online data about vehicle's positioning and traffic conditions, and traffic congestion and accident prevention, among others, are considered.

Some smart communities center their attention on elderly people, for this reason, smart mobility systems have been implemented including aspects such as the monitoring of public transportation mobility [13]. Additionally, smart traffic systems have been designed for accident prevention, particularly for elderly people traveling alone. For this, special cars with devices emitting alarms -signaling within a reasonable response time- regarding adequate distances have been created so elderly people can know up to what extent they can move their vehicles when facing any inconvenience [14].

Other smart community projects developed in different countries involve smart mobility features. In 2010, the US and Japan launched Energy Smart Communities Initiative (ESCI), a project with four main pillars including smart transportation, which in this case seeks for environmentally friendly and efficient ways of transporting people and goods [15]. The target is to reduce travel times, costs, energy consumption, and greenhouse gas emissions. To achieve this, two transportation networks with efficient energy use are implemented, one for cargo and the other for passengers. Furthermore, it is possible to perform traffic management through roadmaps [16].

Another proposal is developed by the Japan-Spain Innovation Program -JSIP and established by the New Energy and Industrial Technology Development
Organization -NEDO and the Center for Technological and Industrial Development -CDTI in Spain, which funds initiatives for joint technology cooperation projects between Japanese and Spanish companies [17]. Through this program, collaborative research is performed to demonstrate the advantages, disadvantages, and challenges with regard to smart communities. The main purpose of the project is to achieve the reduction of energy consumption for public bus transportation systems in the city of Málaga. For this, electric buses are introduced to the system; besides the abovementioned reduction, the buses offer a comfortable, fast, and inexpensive service. Moreover, this public transportation system has complementary services for passenger on board: wi-fi, informative apps, improved accessibility for visual and motor disabilities, and faster payment methods based on Near Field Communications -NFC [18].

Regarding smart mobility, Toyota's project Sustainable Mobility and Smart Communities should also be mentioned. Some guiding principles of the project include an efficient use of transportation system, lowcarbon emissions, the introduction of next generation vehicles, next generation traffic infrastructure, smart solutions of traffic congestion, and the development of traffic data management systems [19].

To conclude, mobility and transportation features in smart communities are essential because new services can be incorporated or existing aspects can become easier so as to improve inhabitants' lives, for instance, the option of booking bus or taxi tickets, positioning and data control of vehicles, accident prevention, traffic congestion alleviation, uniform and rapid vehicle flow, and finally, car parking, bus station monitoring, as well as a fast and effortless transference of passengers between different kinds of public transportation [20].

\section{Smart Government}

It seeks government transparency by granting public access to every government process and database through the implementation of ICT and other technologies. In other words, it pretends to achieve a more efficient interaction between citizens and government.

A clear example of improved interactions is the creation of smart communities in small rural islands of the Caribbean where the use of multi-access centers for the community or kiosks were implemented (MCAC) in libraries, touristic information centers, and post offices [21]. These were introduced as a technological alternative of the government to grant citizens access to services and information through ICTs.

Likewise, similar projects have been executed allowing Citizen-Government interaction, like the established by President Obama's Government in 2009 in which government's information was published online [7] through the creation of the Open Government 
Platform -OGPL, so in this way, every citizen could have access to information, mainly [7]. This method of connecting people with the local government is one feature of smart communities that acknowledges citizen participation in order to improve decision-making processes [11].

\section{Smart Economy}

This aspect intends to achieve greater economic efficiency by using ICTs in companies and businesses. Within this, telecommuting, temporal company association, and coworking, among others, are highlighted. Especially because smart communities need not only to create opportunities to "save energy, reduce gas emissions, and energy billings; but also to foster employment" [15]. This means that, within a smart community area, job opportunities can be created, for instance, in construction [15].

\section{E. Communication Infrastructure}

The intention is to introduce communication technologies that enable systems, people, and devices interconnection, thus, offering permanent access to information and services from any place.

These technologies can be personal as Bluetooth and Zigbee, local as wi-fi, or metropolitan as WIMAX and LTE. To illustrate, to interconnect wireless sensor networks in charge of monitoring different aspects, communication technologies such as ZigBee [13] and wi-fi [12], [13], [22] can be used, which in most cases are also used to provide internet communication in smart communities [12], [23]; for the interconnection of dispersed points, as in the case of metropolitan area networks, WIMAX [17], [24] or LTE are widely known. In any case, an adequate communication infrastructure is fundamental so that fast, efficient, and reliable communication can happen.

\section{F. Environmental Management}

Describes the method to protect the environment and preserve renewable resources using smart systems. Examples of this are: the implementation of technologies that allow natural environments monitoring rivers, forests, atmosphere; recycling technologies; pollution lessening technologies; the use of alternative energy sources -sun and wind; water reuse systems; and the use of green appliances and vehicles, among others.

Most smart communities intend to reduce energy consumption; some have managed to lower energy consumption of smart system elements, like WSN nodes [12] using energy harvesting devices. Similarly, Energy Smart Communities -ESCI and APEC Smart Grid Initiative -ASGI in China pretend to develop smart community projects that include ad- vanced high-efficient technologies for energy storage, renewable energy sources, and control systems for more efficient energy consumption [16]. In Japan, several government entities have introduced the Smart Community Project in four cities: Yokahama, Toyota, Keihana, and Kitakyoshu; the implementation of different systems for energy efficiency is their main objective [25]. In New Mexico, USA, a solar energy system is the new alternative for energy, and a battery system serves as storage unit [26].

Likewise, many smart community projects aim at saving other resources. Málaga's smart community seeks to save not only energy but also water and gas through smart meters, energy storage, and distributed generation of renewable sources, moreover, intends to reduce gas emissions by using electric vehicles [17]. Most smart community projects developed by NEDO, expect to accomplish smart power and water systems, energy saving and recycling technologies, and atmospheric and river monitoring schemes [20]. For instance, Toyota's smart community Project, besides recommending renewable energy use and high-efficient energy systems, tries to achieve a pollution-free environment and a recycling-oriented society [12]. In Lyon, France, the smart community demonstration project has established not only monitoring and control energy consumption systems but also some methods that intend to achieve zero carbon emissions in transportation systems [27].

\section{G. Social Management}

This aspect covers all the smart services that concede wellness and comfort to society. Within social management, topics related to health, security, culture, and comfort are attended.

The majority of smart communities integrate any kind of smart health system; for example, the aforementioned Aware community includes a telemedicine system that enables patient monitoring in terms of blood pressure, weight, permanent activity, and recording medication allocation. Also, a telenursing system is included via video conference for a daily monitoring of patient's activities and condition, and the corresponding record database update [13]. Other smart community projects include Remote Health Monitoring, entitling health providers with a permanent monitoring of patient's parameters through medical alert systems and wireless communication technology in order to provide opportune and accurate medical attention when abnormal health signs are detected [28]. Finally, IBM has created a smart medical attention system that allows patient's information transference in order to be checked by remote doctors, as well as establishing links between hospitals to obtain expert advice [14].

In this way, wellness and security aspects are included in smart community projects in search of the improvement of the quality of life [13], [19]. 


\section{H. Human Interaction Systems}

This aspect comprehends the use of ICTs as tool for human interactions like communication among users or members of a community, education, service management, and employment or business networks, etc. Good examples of this application are platforms such as Facebook and Twitter [7].

For many authors [29], [30], [31], social networks have shaped a new social interaction and citizen organization space, as through them, new spaces for participation and communication have been created Furthermore, work and community support can be accomplished using these platforms [32]. For these reasons, some smart communities introduce social network platforms based on the Internet of Things of fering a cost-free platform for inhabitants of the community and enable them to interact with other people locally [22].

\section{Smart Buildings}

This feature deals with the use of smart systems in buildings, such as domotic systems, home automation, regulation and control of events and home elements, security, and telecommunication system management. All these can be installed in homes, office buildings, schools, and hospitals, among others.

Many smart communities include in the design of smart housing traits to manage and control illumination, temperature, energy consumption systems, health monitoring, and security systems, among others [13], [14], [22]. Additionally, as it was previously established, domotic services are not restricted to houses, they can also be installed in any kind of building in a smart community to provide different services -education, health, offices, government [17], [20].

\section{J. Big Data Analysis}

Smart systems and ubiquitous life create a great flow of data which require processing and storing. In this sense, a management system for Big Data analysis is necessary, maybe through cloud computing. NEDO's projects use the cloud to process and store data generated in the community [17], [20].

\section{Urban and Mobility Analysis}

There is still not a clear definition of urban analysis today; however, it is based on terms and concepts suggested by different authors. Meanwhile, it can be defined as the differentiation and separation of the parts of the city until its principles or elements are known; the aim is to understand the past and the present so as to plan the future [33]. This means urban analysis seeks to study the different urban elements of a city to generate improvement plans in terms of citizens' quality of life.
Many are the aspects to consider in urban analysis; nevertheless, this work is centered on mobility, mainly, the improvement of traffic management and the planning of public services location.

According to [34] "mobility is the movement of people, regardless the means they use; mobility is bound to people who need or want to move, no matter the way they do it". For [35], "mobility measures the journeys people or goods make in a specific system or socioeconomic milieu; includes the space and time in which these trips occur, the motivation originating them, and the means used". Mobility comprises or takes into account various parameters like: number of trips, vehicles or passengers per day, average travel time, ease to make trips -in terms of time and distance, people's accessibility to transportation means, incomes, gender, age, occupation, and educational level, among others [35], [36], [37].

People move within cities with the purpose of making activities inside or outside their homes. In order to perform activities outside them -work, study, shop, visit friends, people can either walk or, use mechanical transportation means like bicycles or motor vehicles such as buses, motorcycles, cars, trains, and subway, among others [37]. Daily mobility brings benefits like the possibility to access to goods and services, but it can also bring negative consequences as accidents, pollution, and traffic congestion [34], [37]. According to previous information, one of the main objectives of creating smart communities is to make its members enjoy from a superior quality of life; so agreeing with [37] "it [should] encompass adequate mobility conditions of people and goods".

From urban analysis it is possible to understand the mobility of a city; for instance, to accomplish the description of the trips made by individuals and the type of transportation required in order to do so, it is necessary to comprehend how the city is structured, how the activities are distributed in the different spaces, and which factors are influencing the most people's mobility and their transportation choices [37]. In this sense, it is plausible to say that for citizens to access efficient and quality goods and services, urban space must be apt and equitable for the inner mobility of all its inhabitants. To accomplish this, the process should start with a citizen mobility analysis within the urban space.

\section{Citizen Mobility Pattern Analysis}

Mobility pattern makes reference to transportation behavior, which deals with the trips made from one place to another within an urban area, and to transportation participation, meaning aspects like transportation modes and the quantity of trips. Mobility pattern is defined by understanding the departure and arrival information of every passenger, the decision of passenger flow distribution in a given area, and the connections within the urban structure [39]. In other words, the mobility pattern enables the classification of individual or group mobility within an urban space. 
Citizen mobility patterns are normally analyzed through a statistical analysis of the trips individuals make so as to produce detailed behavior profiles of the journeys completed. Besides this, some parameters like trip motivations, transportation means, travel times, mileage, among other features are assessed to establish differences between mobility patterns.

In addition, assessed parameters can be related to space, time, and activities [40]; e.g., visiting sequences of given places are assessed -residential, commercial, service, and education areas, working places, and leisure centers, as well as citizens' flow during different times and days of the week.

When activity factors are taken into account in mobility analyses, it is possible to call them 'activity patterns'. It is "the result of the interconnection of individual factors, the interaction with other individuals, and external factors, such as the environment and the social structure" [41]. Within activity patterns, the following are considered: "socioeconomic attributes, as well as the individual's needs, life values, preferences, attitudes, prejudices, and habits" [41]. While the mobility pattern contemplates a person's consecutive trips, the activity pattern considers the chain of activities that person performs during the journey. As the activity pattern involves the mobility pattern, this work will treat them interchangeably.

\section{A. Mobility Patterns}

Different methods afford a suitable data collection and analysis on citizen mobility. Among them, the survey method has been the most used; however, it is not a suitable method in this case because it is not systematized. Nonetheless, "current technologies like smart card systems and smartphones, allow a more detailed data collection of individual passengers' movements. This enables the possibility of analyzing consecutive trips; hence, the time a passenger spends in a specific place" [42].

Now, some of the methods used for this purpose will be described:

1. Smart Cards. A smart card is similar in appearance to a credit card and it can be used to pay for the trips in public transportation; substituting traditional tickets or magnetic stripe cards. These cards have a unique serial number that identifies them and they can be registered under a person's name or remain anonymous. Usually, people swipe it on the card reader located next to the bus driver when going on the bus. Smart cards can be loaded with money which will be 'stored' in it and every time the passenger uses the transit system, the fare will be deducted from the 'stored value'. Cards can also store information related to its use, e.g. transaction's date and time, stop or station where the transaction took place, and the type of transaction carried out [42], [43].
Smart cards produce high-quality data about public transportation trips and the people using the service, i.e., time, origin and destination data of the trips. This information is used to analyze the passenger's travel behavior, so public transportation service suppliers can produce statistics in order to build a scheme of the trips made during the day -or more, and thus, examine trips' behavior. Based on this, smart cards become a great asset to analyze and predict passengers' trip patterns by providing objective and real data of their mobility. In this way, smart cards allow to predict capacity and demand within a given time, as well as location in the transportation network [43], [44].

Several methods for mobility analysis using the data collected by smart cards can be used. Table I displays some.

TABLE I. Methods For Mobility Analysis Using Data Collected By Smart Cards

\begin{tabular}{|c|c|}
\hline Paper & Method \\
\hline $\begin{array}{l}\text { Detecting } \\
\text { Activity } \\
\text { Patterns from } \\
\text { Smart Card } \\
\text { Data }\end{array}$ & $\begin{array}{l}\text { First, a clustering analysis is carried out to } \\
\text { detect which time lapses contain sufficient } \\
\text { activity measurements. Then, a tree-based } \\
\text { algorithm is used to tag activities and analyze } \\
\text { activity chains of individual passengers [42]. }\end{array}$ \\
\hline $\begin{array}{l}\text { Individuals } \\
\text { among } \\
\text { commuters: } \\
\text { Building } \\
\text { personalised } \\
\text { transport } \\
\text { information } \\
\text { services from } \\
\text { fare collection } \\
\text { systems }\end{array}$ & $\begin{array}{l}\text { A passenger differentiation is performed } \\
\text { to users of the public transportation } \\
\text { infrastructure in London through clustering } \\
\text { analysis in order to estimate individual travel } \\
\text { times. The analysis identifies and visualizes } \\
\text { emergent groups of people sharing similar } \\
\text { features; indirectly captures individual } \\
\text { features of passengers; and in this manner, } \\
\text { estimates individual travel times accurately } \\
\text { [45]. }\end{array}$ \\
\hline $\begin{array}{l}\text { Measuring } \\
\text { transit use } \\
\text { variability } \\
\text { with smart- } \\
\text { card data }\end{array}$ & $\begin{array}{l}\text { Shows smart card's data potential to measure } \\
\text { spatial and temporal variability of public } \\
\text { transportation use via data from different } \\
\text { kinds of smart cards and clustering analysis } \\
\text { in order to identify typical temporal patterns } \\
\text { of trips [46]. }\end{array}$ \\
\hline $\begin{array}{l}\text { Travel } \\
\text { patterns } \\
\text { analysis } \\
\text { of urban } \\
\text { residents using } \\
\text { Automated } \\
\text { Fare Collection } \\
\text { System }\end{array}$ & $\begin{array}{l}\text { A new method to recognize passenger flow } \\
\text { direction is proposed so as to understand } \\
\text { travel pattern dynamics in daily mobility of } \\
\text { urban residents. The purpose is to contribute } \\
\text { in the planning and management of facilities } \\
\text { and urban services. The method uses a pattern } \\
\text { recognition model to obtain the characteristics } \\
\text { of every metro station (residential, work, or } \\
\text { mixed-use areas). Afterwards, a recognition } \\
\text { model for passenger flow direction is used to } \\
\text { find/identify the groups in residential areas } \\
\text { stations. Finally, in order to locate origin- } \\
\text { destination directions of passenger flow, origin } \\
\text { and destination stations are represented in a } \\
\text { different colors in Google Maps [47]. }\end{array}$ \\
\hline $\begin{array}{l}\text { Understanding } \\
\text { individual } \\
\text { and collective } \\
\text { mobility } \\
\text { patterns from } \\
\text { smart card } \\
\text { records: A } \\
\text { case study in } \\
\text { Shenzhen }\end{array}$ & $\begin{array}{l}\text { Temporal mobility patterns are inferred } \\
\text { through statistics collected from bus and } \\
\text { metro smart cards in different days. Spatial } \\
\text { and temporal patterns are found based on a } \\
\text { daily detailed check-in and check-out analysis } \\
\text { from different metro stations. Connections } \\
\text { between the different stations are measured } \\
\text { via an origin-destination matrix. With the } \\
\text { in-out records of the time marks and places } \\
\text {-for every individual, the week's sampling } \\
\text { period is calculated, as well as the passengers' } \\
\text { frequency. The objective is to illustrate the } \\
\text { regularity of mobility patterns [48]. }\end{array}$ \\
\hline
\end{tabular}

Source: Authors 
2. Mobil Devices with Geolocation. Geolocation enables to calculate the position of an element in a specific real-world place through its geographic coordinates. There are two basic ways to achieve this: through a device assisted by a global positioning satellite network like Global Positioning System -GPS or Global Navigation Satellite System-GLONASS; or by calculating the position of mobile nodes through internet -cellular phones and other third generation devices [49]. The review in this paper focuses on devices working with GPS network.

For the location process, a GPS device emits a signal indicating the time and the information of the place where it is positioned. Satellites receive this signal and three of them compare it in order to calculate its position. This method is known as triangulation. This method uses "a set of $3 \mathrm{G}$ nodes with a known position. Each node must be able to determine the direction in which the point to be located is. In order to do so, the signal emitted by the mobile device should be captured via a directional antenna. This process allows obtaining the signal's direction in relation to one of these $3 \mathrm{G}$ nodes. To estimate the distance, a second antenna located at a known distance from the node is used; it establishes the direction in which the signal is. Finally, a triangle is outlined using the information regarding both directions, and the direction and distance between the two antennae" [49].

Similarly, by measuring the intensity of radio frequency signals emitted by a mobile device, a position can also be estimated. For this, two methods can be used: triangulation and trilateration. Contrary to triangulation, the latter does not involve the measurement of angles "measures the signals distance using three $3 \mathrm{G}$ antennae that shape three spheres in the surface where the measurement point is; two spheres intersect in two points; the third establishes the point where the mobile device is" [49].

These methods and the different tracking, collection, and data storage systems based on location have fostered positioning data analysis of objects in motion -vehicles, people, and animals, among others. Trajectory data analysis is now simpler thanks to easier data collection processes enabled by mobile devices [50], [51].

Mobile devices, especially phones, may have GPS features or sensors integrated, thus, encouraging mobility data collection. Also, passive data collection methods, like detailed phone call records provided by mobile telephone companies, are likely to be used [52], [41].

A broader use of mobile networks, GPS devices, and wireless access points allow the capture of big data of people and cities in real time. These spatiotemporal data collection systems are useful for human mobility analysis, granting more efficiency and response capacity in urban policies. Moreover, contrary to other mobility data collection methods, geolocation is cheaper, provides samples with more information, updates more frequently, and has more spatial and temporal coverage, due to these reasons, a large number of researches have focused on the impact of mobile devices in human mobility patterns [41], [50], [52], [53], [54].

Table II summarizes some methods used for data analysis through geolocation mobile devices.

Table II. Methods For Data Analysis Using Geolocation Mobile Devices

\begin{tabular}{|c|c|}
\hline Paper & Method \\
\hline $\begin{array}{l}\text { Advanced Knowledge Discovery } \\
\text { on Movement Data with the GeoP- } \\
\text { KDD System }\end{array}$ & $\begin{array}{l}\text { An integrated platform for complex analysis of mobility data, called GeoPKDD, is used. The sys- } \\
\text { tem combines spatio-temporal query capabilities with data mining and semantic technologies to } \\
\text { provide a comprehensive support for mobility discovery and knowledge procedures. This platform } \\
\text { enables the knowledge extraction of massive trajectory datasets [50]. }\end{array}$ \\
\hline $\begin{array}{l}\text { Correlating Mobile Phone Usage } \\
\text { and Travel Behavior - A Case } \\
\text { Study of Harbin, China }\end{array}$ & $\begin{array}{l}\text { Provides a deeper understanding of how mobile phones usage correlates with individual travel } \\
\text { behavior by exploring the correlation of mobile phone call frequencies and three indicators of } \\
\text { travel behavior: radius, eccentricity, and entropy, taking into account three aspects of the activity } \\
\text { behavior: scale, shape and randomness. Additionally, individual attributes are examined -age, } \\
\text { gender, and income level, as well as supraindividual features like socio-institutional and physical } \\
\text { aspects. The dataset provides three types of information directly registered by each mobile phone } \\
\text { user: (1) mobile phone use; (2) individual features; (3) spatio-temporal points for a given time } \\
\text { lapse [54]. The data analysis was carried out as follows: in first place, all the data was divided } \\
\text { in groups in accordance with usage frequency -using dialed and received calls information, i.e., } \\
\text { people belonging to the same group have the same call frequency. From this point, the average } \\
\text { movement radius, eccentricity, and entropy of each group were estimated. Afterwards, the corre- } \\
\text { lation between mobile phone usage and each of the three indicators was achieved through linear } \\
\text { regression [54]. }\end{array}$ \\
\hline $\begin{array}{l}\text { Intra-urban Human Mobility Pat- } \\
\text { terns: An Urban Morphology Per- } \\
\text { spective }\end{array}$ & $\begin{array}{l}\text { This paper determines if human mobility patterns inside cities are affected by two urban mor- } \\
\text { phological characteristics: compactness and size. Mobile phone data was collected in eight cities } \\
\text { from Northeast China and used to identify people's movement trajectories. Massive mobil phone } \\
\text { data provides a wide coverage and detailed description of individual's movements in space and } \\
\text { time. Two datasets are considered for the analysis: a basic geographic dataset used to shape } \\
\text { urban areas; and a mobile phone record dataset used to reconstruct individual's spatio-temporal } \\
\text { trajectories [55]. }\end{array}$ \\
\hline
\end{tabular}




\begin{tabular}{|c|c|}
\hline $\begin{array}{l}\text { Mobile and Wi-Fi Geolocation Us- } \\
\text { ing Google Latitude }\end{array}$ & $\begin{array}{l}\text { This paper puts forward a system based on Google Latitude to outline the location of a specific } \\
\text { wi-fi tower while locating the approximate position of wireless mobile devices without the use } \\
\text { of GPS. Using wi-fi information data to estimate the location of towers separately, the absolute } \\
\text { position of the device is achieved [56]. }\end{array}$ \\
\hline $\begin{array}{l}\text { Sampling Urban Mobility through } \\
\text { On-line Repositories of GPS Tracks } \\
\text { Categories and Subject Descriptors }\end{array}$ & $\begin{array}{l}\text { A series of guidelines to collect and filter short-term mobility traces from public access reposito- } \\
\text { ries of GPS tracks is proposed to study urban mobility on a large scale. All mobility traces were } \\
\text { gathered from a group of files from Nokia Sports Tracker service, which enables users to track } \\
\text { their routes, speed, and times while performing different activities [57]. }\end{array}$ \\
\hline $\begin{array}{l}\text { Semantic Trajectories : Mobility } \\
\text { Data Computation and Annotation }\end{array}$ & $\begin{array}{l}\text { In this paper a semantic model was designed and implemented, as well as the platform for the } \\
\text { trajectory analysis of three different kinds of moving objects - cars, taxis, and people with smart- } \\
\text { phones. The model uses the spatio-temporal trajectory gross data delivered by the GPS and se- } \\
\text { mantic representations of the highest level to offer a structured vision of mobility data [51]. }\end{array}$ \\
\hline $\begin{array}{l}\text { Understanding Individual Mobil- } \\
\text { ity Patterns from Urban Sensing } \\
\text { Data: A Mobile Phone Trace Ex- } \\
\text { ample }\end{array}$ & $\begin{array}{l}\text { This paper puts forward methods to extract useful mobility information from mobile phone traces } \\
\text { of millions of users and compares them to vehicle mobility data to investigate individual mobility } \\
\text { patterns within a metropolitan area in Boston [53]. }\end{array}$ \\
\hline $\begin{array}{l}\text { Understanding Monthly Variabil- } \\
\text { ity in Human Activity Spaces: A } \\
\text { Twelve-Month Study Using Mobile } \\
\text { Phone Call Detail Records }\end{array}$ & $\begin{array}{l}\text { This study maps individual mobility patterns in order to deliver new knowledge on human activity- } \\
\text { travel behavior using detailed records of mobile phone calls. Activity locations are measured based on } \\
\text { the coverage area of an operator's base station. Afterwards, activity space is measured taking into ac- } \\
\text { count the places where activities were carried out, and finally, a statistical analysis is performed [41]. }\end{array}$ \\
\hline
\end{tabular}

Source: Authors

3. Data Mining of Geotagged Messages. Geotagging allows adding location tags to a file or website, this means, consists of the aggregation of geographic information so as to position an item in the space. This information can be given as coordinates -longitude and latitude, or simpler information as place names, addresses, or zip codes [58].

Several social networks have geotagging apps and they are being used to gather mobility data. These social networks are known as LocationBased Social Networks -LBSN; Foursquare, Facebook Places, and Google Latitude are among them. These kind of social networks enable users to share an event or activity happening at certain places, basically from any place and any time. An example of this can be an Apple fan publishing geotagged messages when shopping at an Apple Inc store. Besides LBSNs, there are location integrated services in social networks equally useful for mobility data analysis [52], [59], [60].

Data gathered from LBSN can be captured permanently using different positioning tools as mobile phones, wireless network devices, and GPS devices. This information about individual's mobility behavior is granting more accurate mobility pattern studies since more trajectory areas and people can be covered. These mobility data have been used for different applications like traffic prediction and city's planning, as well as analyzed using data mining [61].

Data mining enables information extraction from a dataset and its subsequent transformation in an understandable structure for a later use [62]. This means, the application of machine learning tools, among other methods, to find important patterns as of big data from any data storage system [63]. Among the most widely used methods for this type of data analysis are data mining and trajectory learning algorithms, for instance, clustering, classification, atypical value detection, convoy search, and sequential pattern mining [64],[65].

Table III mentions some data analysis methods used by some authors.

When comparing the three methods for the collection and subsequent analysis of citizen mobility patterns, it is concluded that smart cards produce large amounts of detailed data about on board public transportation activities and provide real and unbiased information regarding passengers' mobility. Through this data collection method, large samples can be gathered for long periods of time. Contrary to geolocation records, smart cards provide detailed data of a city's transportation habits. Within this dataset, aspects such as travel times, locations, modes, travel origins and destinations, fares, and selected routes, among others, can be established to have a clear idea of passengers' behavior, thus, the performance of the transportation system can be assess by analyzing and predicting users' travels. The system's capacity demand and the location in the transportation network can also be predicted. Additionally, spatio-temporal variability of public transportation usage can be measured. All these help to assess travel behavior variability for different sections of the population on a specific transportation network.

Nonetheless, this method presents some inconveniences. For instance, some public transportation systems using smart cards do not register destinations and travel times; also, travel motivations are unknown, though sometimes they can be inferred by knowing the destination and the area the station belongs to -commercial, residential, leisure, etc. Another limitation is that collected data is not available until a day after, thus, becoming a histori- 
Table III. Analysis Methods For Data Gathered Through Data Mining Of Geotagged Messages

\begin{tabular}{|c|c|}
\hline Paper & Method \\
\hline $\begin{array}{l}\text { Evaluating Geo-Social Influence in Location-Based So- } \\
\text { cial Networks }\end{array}$ & $\begin{array}{l}\text { Two approximation algorithms are used -GI and DNE to estimate user's in- } \\
\text { fluence effectively. Also, sampling techniques and the threshold algorithm to } \\
\text { retrieve top-k influential events from groups sharing similar features [59]. }\end{array}$ \\
\hline $\begin{array}{l}\text { WhereNext: A Location Predictor on Trajectory Pat- } \\
\text { tern Mining }\end{array}$ & $\begin{array}{l}\text { WhereNext method is put forward so as to predict the next location of a mov- } \\
\text { ing object using previously extracted movement patterns through the trajec- } \\
\text { tory pattern algorithm developed in [66]"mendeley": : "previouslyFormatted- } \\
\text { Citation": "[63]" \}, "properties": }\{\text { "noteIndex": } 0\} \text {, "schema": "https://github. } \\
\text { com/citation-style-language/schema/raw/master/csl-citation.json" \}, which } \\
\text { uses clustering of similiar features [64]. }\end{array}$ \\
\hline $\begin{array}{l}\text { Who, Where, When and What : Discover Spatio-Tem- } \\
\text { poral Topics for Twitter Users }\end{array}$ & $\begin{array}{l}\text { Mobility behavior of micro-blogging (Twitter) service users is modeled with } \\
\text { a collection of geotagged messages or 'tweets'. A probabilistic model called } \\
\text { "Who, Where, When and What" is used to discover individual mobility behav- } \\
\text { iors regarding spatial, temporal, and activity aspects [40]. }\end{array}$ \\
\hline $\begin{array}{l}\text { Citizen as a Sensor: The Barcelona Urban Mobility } \\
\text { Use-case }\end{array}$ & $\begin{array}{l}\text { This paper poses two complementary ways of using human's detection ca- } \\
\text { pabilities in order to understand their mobility patterns in a urban context: } \\
\text { information extraction from social networks and the acquisition of accurate } \\
\text { position information through gamification techniques. For the system's mod- } \\
\text { eling, graph theory algorithms are applied [67]. }\end{array}$ \\
\hline $\begin{array}{l}\text { The Places of Our Lives: Visiting Patterns and Auto- } \\
\text { matic Labeling from Longitudinal Smartphone Data. }\end{array}$ & $\begin{array}{l}\text { Algorithm inference and clustering is presented to describe the places people } \\
\text { visit on a daily basis. The paper is based on the data continuously recorded by } \\
\text { smartphones. In first place, human mobility is studied from the sequences of } \\
\text { places visited; and secondly, automatic geotagging problem is addressed from } \\
\text { smartphone data without the use of any geolocation information [52]. }\end{array}$ \\
\hline
\end{tabular}

Source: Authors

cal data source. However, these data are useful to plan the transportation network, improve its performance, and support service planning.

The geolocation method through mobile devices allows individual and detailed data collection of real-time movements in a city, and as mentioned previously, provides large information samples, updates more frequently, and has broader spatio-temporal coverage. These aspects allow the analysis of consecutive travels and the time an individual spends at a given location. These location traces are constantly recorded and enable the description of many individual mobility aspects which cannot achieved using other methods. Human or vehicle movement in a definite area can be observed through the digital traces left by mobile devices, which are collected by existing wireless network infrastructures, this fact brings an additional positive feature to this method: low cost. Another positive aspect is related to location accuracy since a cell position or latitude and longitude position can be acquired with a GPS. However, data gathered through this means also have some disadvantages. Due to privacy matters, it is not possible to count on demographic and socioeconomic information; likewise, results may not represent a random sample of the population, data's resolution can be low, datasets are not designed for modeling purposes, and regularly, their format is not easy to use, hence, limiting gross data usefulness. Nevertheless, real-time data updates offer more reliable and traceable indicators of urban performance, hence, granting more efficiency and response capability in urban policies.
Data mining of geotagged messages is more scalable and faster. This method takes advantage of the fact that many people want to share information with others online. Many services like Foursquare, Facebook Places, Twitter and Google Latitude, among others, enable people to share events and their location voluntarily. In other words, people can post through short messages information about an activity or event: location, time, and description allowing the study of spatio-temporal preferences of users. This method enables more complete information than others since besides letting to know the person's location, the activity and the time spent can also be known. However, the inconvenience resides on the impossibility of attaining an individual's complete trajectory sometimes because eventually people do not post location information.

Finally, mathematical methods used to analyze mobility data include different types of algorithms such as clustering, inference, and tree-based algorithms, among others. The most used are clustering algorithms as they classify data in accordance with similar features, in this particular case, similar mobility patterns.

\section{Applications}

Human mobility undoubtedly is a substantial aspect in a city, so understanding its patterns is crucial for the planning and management of facilities and urban services. Ubiquity and the different systematized data collection methods have delivered great datasets to analyze citizens' mobility patterns and generate diverse applications within the urban con- 
text as tourist attractions identification, urban planning, bicycle traffic management, virus propagation understanding, and traffic and congestion supervision [45], [48]. This review specifically aims at applications for the improvement of traffic and service location planning in cities.

Population density growth in cities has created great traffic congestion problems, for this reason, traffic management has become a fundamental aspect. Taking into account mobility data collected via automated methods, it is probable to improve traffic management in cities. Several smart city projects include this aspect; in Spain, Santander, Málaga, and Zaragoza cities, within the smart cities project called 'Ciudad 2020', are designing services focused on citizens' needs and demands through the use of transportation data coming from sources as mobile applications that allow recording events in a global platform, and social networks which are used to share locations and multimedia contents like messages or photos. This large amount of data is generated by citizens when using urban infrastructures. The purpose is an efficient mobility management supported by ICTs. An example of this is a tool designed to estimate the best routes combining different public -bus, streetcar, public bicycle, etc- and private transportation means [68].

Many cities in the world, especially in Europe, have implemented a traffic management system from Siemens called Siemens Traffic Solutions. It compiles traffic information of urban centers from different storage sources for citizens to access so as to know current traffic conditions via smartphones, internet, or navigation systems, as well as through variable-message signs-VMS in roads. This solution has already been implemented in cities like Berlin, Cologne, Cantons of Switzerland, London, Budapest, Bangkok, Huston, and Bregenz, among others [69].

In Hong Kong, a general system for traffic and public transportation has been implemented; the Traffic Management and Information Center-TMIC includes a traffic information system that sends wireless information to VMS, smartphones, and automotive navigation systems. It also includes vehicle tracking and fleet management system based on GPS devices outspread in bus lines. The purpose of this system is to eliminate congestion and unnecessary travels by granting users access to the public route plan and choose the best transportation mode before travelling [70].

In Colombia, Medellín city aims at trafiic optimization through the implementation of the Intelligent Mobility System of Medellín -SIMM. "The District Mobility Secretary of Medellín, using new information and communication technologies for the Intelligent Transportation Systems, collects, processes, and analyzes traffic data to develop strategies and actions towards the reduction of negative effects of traffic in order to improve service schedules, regula- tion, and traffic control and, in this way, decrease accident rates" [71]. Some examples are the implementation of VMS in roads to plan routes and the permanent connection through the social network Twitter to solve mobility queries instantly.

Service location, also known as Location-based Services -LBS, offers a service based on instant location information of the user at any moment. "Users consult geographic information -elevation, latitude, and longitude- of the current position by the location data provided by mobile devices so as to attain information regarding services offered in the surroundings; for this, a data base is checked" [72]. LBS deliver spatial and social information of the services like position, description, and specific information of the service.

Several studies use mobility information to plan service location. Public transportation is a service that finds location very useful. For instance, a system using human trajectory data to create an Individual Mobility Pattern Library -IMPL is proposed based on real data from smart cards in Beijing [73]. This system has been implemented as an application to estimate unshipping information; in this way, users of transportation systems can have updated information about routes and know which ones have less passenger flow. Another study analyzes travel patterns of London's underground to plan routes and predict personalized travel times for the system's users [74]. Chicago's public transportation system CTA offers bus and traditional train transportation in Chicago and 40 suburbs from the area, so CTA Bus Tracker was developed in order to deliver realtime transportation information [75]. This system uses GPS to locate buses and give specific information like current location and estimated arrival time at a particular station. As this location-based service enables passengers to access real-time information about vehicles in transit using internet via smartphones or similar mobile devices, they can plan their itineraries.

Other applications can also be used to locate other services. Loco-radio is an automotive navigation system using GPS and a geomagnetic field detection module to provide location detection. Audio comes from a personalized geotagged database containing a set of channels for different purposes. This system uses iconic music to represent restaurants; in this way, the application transforms the restaurants surrounding the mobile user in an immersive and interactive audio environment [76]. Likewise, a project called LocON implements a generic platform to provide a set of location-based services via different wireless location technologies [77]. With the positioning data analyzed in the application layer of the platform, decisions are made to control and track events in accordance with the business' logic. LocON has been implemented at Faro airport in Portugal for surveillance purposes. 
Metro Paris Subway, Yelp, and Urbanspoon also deliver location information with the help of automated location functions in smartphones. Metro Paris Subway is a complete travel guide around Paris, France. It provides information in regards with public transportation options and places of interest; includes official metro maps, alerts and notifications, exact location of every station in the map and its distance from where the mobile user is, and finally, a tool to plan metro travels that shows automatically the best route to reach the metro destination. Equally, the user can provide an address in Paris and the application displays the closest stations to the address. Additionally, places of gastronomic -restaurants, cafés, patisseries, leisure, and lodging interest in France can be added. In Fig. 2 some screenshots illustrate how the user visualizes the application in the smartphone. Yelp suggests information about businesses in the area and provides valuable information about them thanks to comments, advice, or photos posted by other users. Urbanspoon allows navigation and information search about restaurants. Besides posts from other users, these two applications include maps and addresses [78].
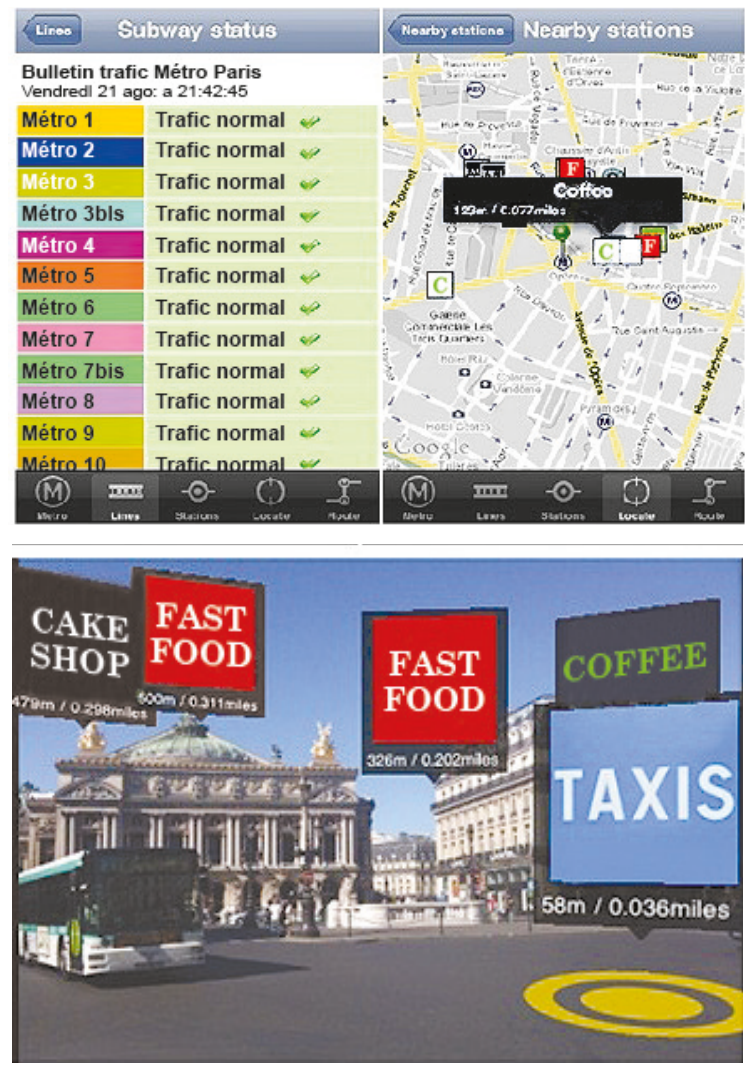

Fig. 2. Metro Paris Subway aplication as seen from the user's smartphone Source: L'application Métro Paris sur iPhone et iPod Touch [79]

\section{Discussion}

Smart communities come as the result of the intention of improving citizen's quality of life via technology. Several aspects are currently being developed as mentioned above. Mobility is one of the most relevant aspects because as population density increases, so does the amount of people in need of transportation, hence, traffic congestion, accident rates, and pollution increases. For this reason -and in order to create solutions- many studies center on citizen mobility analysis.

Data from all the aforementioned researches are being applied to improve the city in traffic management aspects, delivering citizens updated and prompt information related to traffic and available routes at all times. Additionally, these data is priceless for service location planning, as in the case of public transportation route and schedule information and the ease in finding restaurants, parking lots, and leisure places.

Mobile devices' boom has enabled researchers to collect information about users' mobility patterns easily and, at the same time, use these data to offer mobility, traffic, and public transportation information services through applications installed in these devices.

Great traffic congestion problems and inefficient transportation services in many cities around the world have been improved mainly through smart mobility management. The benefits attained are many: road reorganization; the reduction of traffic congestion and pollution; the enhancement of road safety; the creation of alternative public transportation modes, and more accessibility to public transportation services, among others.

Dealing with other research lines related to smart cities in the future would be very productive, especially those involving WSN or interconnected devices through the internet to monitor different environments. The growth of the Internet of Things has encouraged the interconnection of different devices around the world, resulting in a beneficial component for mobility planning in smart cities. Fig. 3 shows a diagram of interconnected devices using the Internet of Things

Some areas related to urban analysis are sensor networks for home monitoring, this is, networks facilitating the connection of multiple appliances that can be managed and supervised through internet. WSN can be implemented in communities so as to monitor surveillance and sanitary attention or for early warning systems -EWS to prevent natural disasters like flooding, earthquakes, or slides since WSN is a good way to monitor threats and offer forecasts about the consequences of an event, hence, reducing the aftermath of natural phenomena. Likewise, these kinds of systems can prevent or cooperate during rescue procedures in urban disasters. 


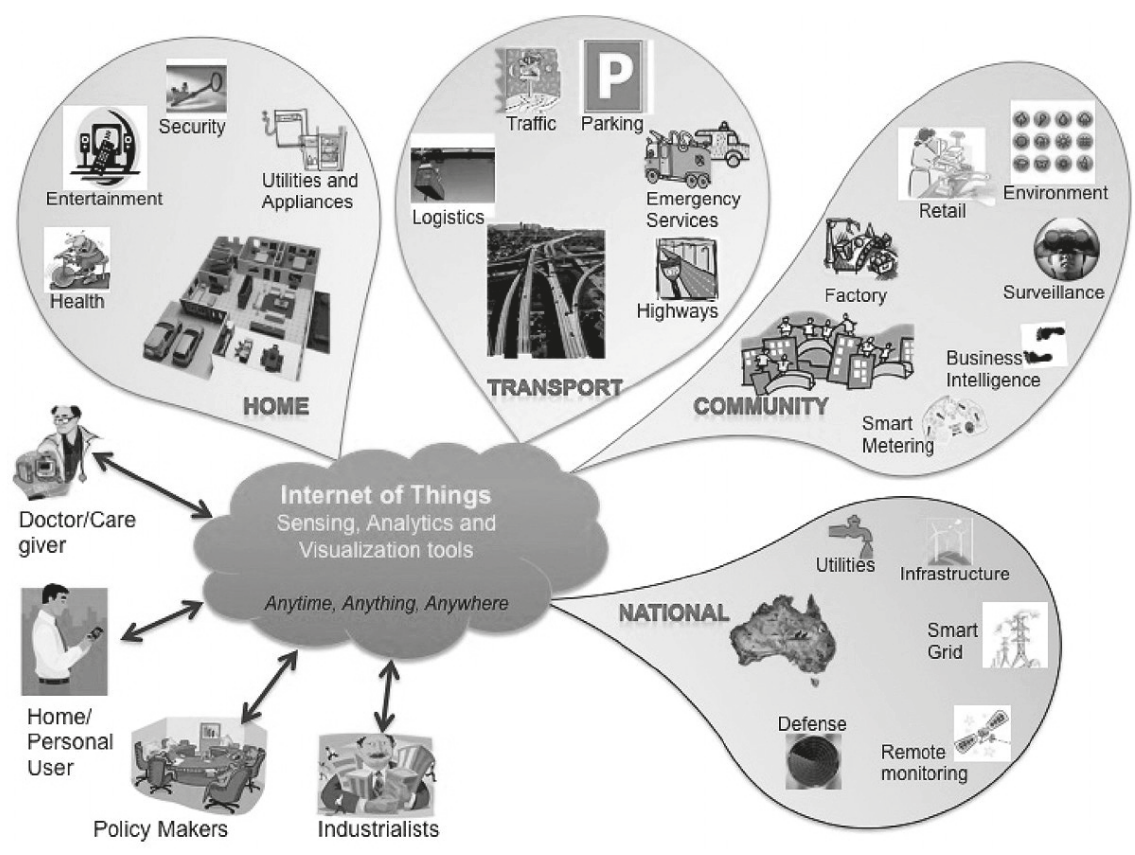

Fig. 3: Diagram displaying applications and devices connected through the Internet of Things Source: Internet of Things (IoT): A vision, architectural elements, and future directions [80].

Structural monitoring helps controlling the safety, integrity, and performance of structures such as bridges, buildings, and highways. These systems work by placing sensors in the structures to detect and locate any damage produced as a consequence of an event. For example, Fig. 4 illustrates a wireless system used to reduce time response in urban search and rescue.

These and more applications can be considered to improve citizens' quality of life worldwide.

\section{Conclusions}

Due to urban growth, communities need new initiatives and strategies in the pursuit of achieving cities that grow in a planned manner. Technology use allows the creation of urban spaces in which organized coexistence and efficient access to services in a com- munity become possible. Mobility also becomes an essential aspect within cities as it grants citizens access to goods and services. The analysis of citizens' mobility patterns through the data collected via automated methods -smart cards, geolocation, and geotagging- fosters the creation of applications that assist in the management of different aspects in cities. Regarding traffic management, mobility pattern analysis promotes the creation of applications to control urban traffic and guarantee all citizens easy access to transportation services. As for location service planning, mobility pattern analysis offers updated and accurate information about location and description of services. Thanks to the experiences of the different pilot projects of smart communities in the world, it is now expected that cities in the future become supported by ubiquitous technology because that will enable citizens to have a high quality of life.

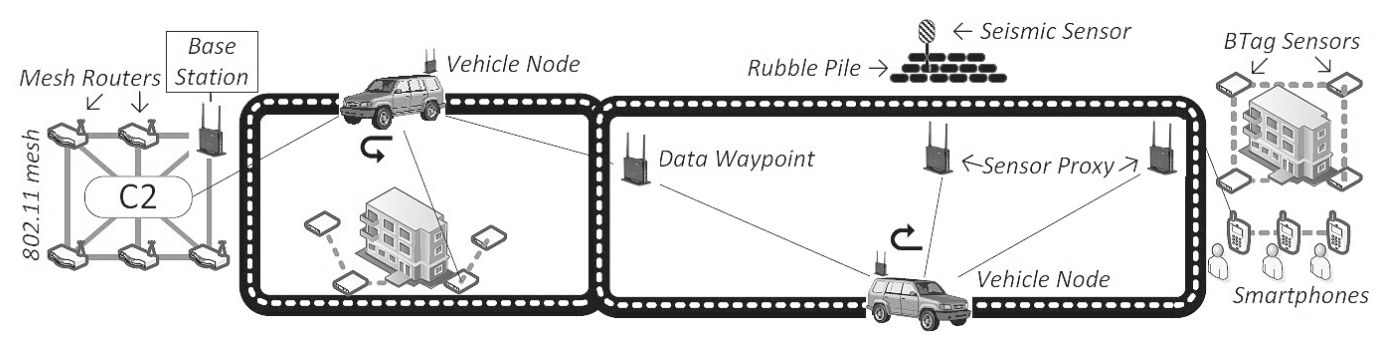

Fig. 4. Wireless system to reduce time response in urban search and rescue Source: A Wireless System for Reducing Response Time in Urban Search \& Rescue [81] 


\section{REFERENCES}

[1] UNFPA, "Estado de la población mundial 2007" Fondo de población de las Naciones Unidas, 2007. [En línea]. Disponible en: http://www.unfpa.org/webdav/site/global/shared/documents/publications/2007/swp2007_spa. pdf.

[2] L. Moreno and A. Gutiérrez, "Ciudades Inteligentes: Oportunidades para generar soluciones sostenibles," CINTEL, 2012. [En línea]. Dsiponible en: http://cintel. org.co/wp-content/uploads/2013/05/01.Ciudades_Inteligentes_CINTEL.pdf.

[3] R. M. MacIver, Community: a sociological study, New York, USA: Macmillan. 1924, pp. 22-23

[4] R. Park and E. Burgess, "Can neighborhood work have a scientific basis?," in The City: Suggestions For The Investigation Of Human Behavior In The City Environment, Chicago: University of Chicago Press, 1967, p. 144.

[5] N. Hataya, "The illusion of community participation: experience in the irregular settlements of Bogotá," Universidad de Londres, 2007.

[6] J. M. Eger, "The Smart Community concept," 2014. [En línea]. Disponible en: http://www.smartcommunities. org/concept.php.

[7] C. Rabari and M. Storper, "The digital skin of cities: urban theory and research in the age of the sensored and metered city, ubiquitous computing and big data," Cambridge J. Reg. Econ. Soc., vol. 8, no. 1, pp. 27-42, 2014. DOI:10.1093/cjres/rsu021

[8] L. Anthopoulos and P. Fitsilis, "Defining a Common Architecture for Urban Development," in Digital to Ubiquitous Cities, 2010, pp. 301-306. DOI:10.1109/ IE.2010.61

[9] J. Ma, L. T. Yang, B. O. Apduhan, R. Huang, L. Barolli, and M. Takizawa, "Towards a smart world and ubiquitous intelligence: A walkthrough from smart things to smart hyperspaces and UbicKids," Int. J. Pervasive Comput. Commun., vol. 1, no. 1, pp. 53-68, 2005. DOI:10.1108/17427370580000113

[10] F. Xia and J. Ma, "Building smart communities with cyber-physical systems," in 1st international symposium on From digital footprints to social and community intel ligence, 2011, pp. 1-6. DOI:10.1145/2030066.2030068

[11] A. Coe, G. Paquet, and J. Roy, "E-Governance and Smart Communities A Social Learning Challenge," Soc. Sci. Comput. Rev., vol. 19, no. 1, pp. 80-93, 2001. DOI:10.1177/089443930101900107

[12] M. Wijnants, W. Lamotte, N. Letor, C. Blondia, E. De Poorter, D. Naudts, S. Verstichel, B. Lannoo, I. Moer man, N. Matthys, and C. Huygens, "An Eco-friendly Hybrid Urban Computing Network Combining Com munity-Based Wireless LAN Access and Wireless Sensor Networking," in International Conference on Green Computing and Communications (GreenCom), 2012, pp. 410-417. DOI:10.1109/GreenCom.2012.66

[13] H. Wactlar, R. Walters, J. Bertoty, and A. Hauptmann, "The Aware Community," in Second International Conference on Future Generation Communication and Networking, 2008, pp. 457-462.

[14] H. Yongjia, "The Plan of Elderly Smart Community: Based on the Concept of Internet of Things," in International Conference on Management and Service Science (MASS), 2010, pp. 1-4. DOI:10.1109/IC MSS.2010.5577525

[15] EWG Secretariat, "2012 EWG Work Plan," Work Plan for 2012: APEC Energy Working Group, 2012. [En línea]. Disponible en: http://www.iisd.org/gsi/sites/default/files/g20lib_apec_2012_ewg43workplan.pdf.

[16] C. Bloyd, "Energy Smart Communities (ESCI) and APEC Smart Grid Initiative (ASGI) Update," Pacific Northwest, 2013. [En línea]. Disponible en: http://www. egnret.ewg.apec.org/meetings/egnret39/[C4] Bloyd ESCI ASGI.pdf.
[17] T. Hidekazu, "The Smart Community System Demonstration Project in Malaga," Nedo, 2012. [En línea]. Disponible en: http://www.nedo.go.jp/content/100455503. pdf.

[18] P. Rodríguez, "Smart Mobility: movilidad inteligente en las ciudades," i-ambiente, 2013. [En línea]. Disponible en: http://www.i-ambiente.es/?q=blogs/smart-mobilitymovilidad-inteligente-en-las-ciudades\#.dpuf.m.

[19] H. Okajima, "Sustainable Mobility and Smart Community," Toyota Motor Corporation. May, 2012. [En línea]. Disponible en: http://www.nedo.go.jp/content/100494310. pdf

[20] NEDO, “Smart Communities' that Link People, Objects and Technologies by means of ICTs to Create Safe, Reliable and Pleasant Social Systems,” 2012. [En línea]. Disponible en: http://www.nedo.go.jp/content/100494623.pdf

[21] W. Unette Sealy, "Empowering Development through E-Governance: Creating Smart Communities in Small Island States," Int. Inf. Libr. Rev., vol. 35, no. 2-4, pp. 335-358, 2003. DOI:10.1080/10572317.2003.10762609

[22] Xu Li; Rongxing Lu; Xiaohui Liang; Xuemin Shen; Jiming Chen; Xiaodong Lin, "Smart community: an internet of things application," Communications Magazine, IEEE , vol.49, no.11, pp.68,75, 2011. DOI:10.1109/ MCOM.2011.6069711

[23] X. Liang, K. Zhang, R. Lu, X. Lin, and X. Shen, "EPS: An Efficient and Privacy-Preserving Service Searching Scheme for Smart Community," Sensors Journal, IEEE, vol. 13, no. 10, pp. 3702-3710, 2013. DOI:10.1109/ JSEN.2013.2263793

[24] ENDESA,"Málaga Smart City Model of sustainable energy management for the cities of the future," Berlin, 2011. [En línea]. Disponible en: http://www.endesa.com/ EN/SALADEPRENSA/CENTRODOCUMENTAL/Publicaciones/Smartcity-Malaga_ENG.pdf

[25] Y. Komiyama, "Smart Communities," METI. Japón. 2011. [En línea]. Disponible en: http://www.enecho.meti. go.jp/notice/event/036/pdf/event036013.pdf

[26] S. Morozumi, "Strategy of smart community in NEDO and New Mexico Japan-US Demonstration Project," New Energy and Industrial Technology Development Organization. Event Report on "Smart Community Summit 2012" and "Smart Grid Exhibition 2012.

[27] NEDO. "Lyon Smart Community," At Confluence of energy and the environment. NEDO. Lyon, 2012. [En línea]. Disponible en: http://www.economie.grandlyon. com/fileadmin/user_upload/fichiers/site_eco/20121121 gl_lyon_smart_community_dp_en.pdf

[28] X. Liang, X. Li, R. Lu, X. Lin, and X. Shen, "Enabling pervasive healthcare with privacy preservation in smart community," in IEEE International Conference on Com munications (ICC), 2012, pp. 3451-3455. DOI:10.1109/ ICC.2012.6363888

[29] M. Castells, "Internet y la Sociedad Red," 2001. [En línea]. Disponible en: http://tecnologiaedu.us.es/cursos/29/html/bibliovir/pdf/106.pdf

[30] H. Rheingold, Multitudes Inteligentes La Próxima Revolución Social. Barcelona: Gedisa, 2004, pp. 14-18.

[31] S. Sacaan, "Las redes sociales y la inteligencia colectiva: Nuevas oportunidades de participación ciudadana," in IV Congreso de la Cibersociedad, 2009. [En línea]. Disponible en: http://www.cibersociedad.net/congres2009/ es/coms/las-redes-sociales-y-lainteligencia-.

[32] W. Sherchan, S. Nepal, and C. Paris, "A survey of trust in social networks," ACM Comput. Surv., vol. 45, no. 4, 2013, pp.1-33. DOI:10.1145/2501654.2501661

[33] C. S. Ferro, "Los paradigmas indiciarios del análisis urbano A propósito del análisis urbano y las escuelas de arquitectura," Arquit., vol. 5, no. 5, pp. 42-53, 2009.

[34] C. Mataix, "El concepto de la movilidad sostenible," Alba, 2014. [En línea]. Disponible en: http://www.fenercom. com/pages/pdf/formacion/05-02-2014-Jornada-sobreMovilidad-y-transporte/01-EL-CONCEPTO-DE-LAMOVILIDAD-SOSTENIBLE-ALBA-INGENIEROS. 
[35] C. Lizarraga, "Expansión metropolitana y movilidad: el caso de Caracas," EURE, vol. 38, no. 113, pp. 99-125, 2012. DOI:10.4067/S0250-71612012000100005

[36] D. Robinson; and G. Banjo,"Rural Transport Policy in Action," World Bank. 1999. [En línea]. Disponible en: http://www.transport-links.org/rtkb/english/Module\%201\%5C1_3a\%20Policy\%20Development\%20Process.pdf

[37] E. A. Vasconcellos, Análisis de la movilidad urbana. Espacio, medio ambiente y equidad, 1st ed. Bogota: CAF, 2010. [En línea]. Disponible en: http://omu.caf.com/media/14683/an\%C3\%A1lisis_movilidad_urbana.pdf

[38] M. Held, Verkehrsmittelwahl der Verbraucher. Beiträge einer kognitiven Motivationstheorie zur Erklärung der Nutzung alternativer Verkehrsmittel. Berlin, D, Germany: Speyer \& Peters GmbH, 1982.

[39] B. Du, Y. Yang, and W. Lv, "Ubiquitous Intelligence and Computing," in IEEE 10th International Conference on and 10th International Conference on Autonomic and Trusted Computing (UIC/ATC), 2013, pp. 127-133.

[40] Q. Yuan, G. Cong, Z. Ma, A. Sun, and N. MagnenatThalmann, "Who, where, when and what: discover spatio-temporal topics for twitter users". in 19th $A C M$ SIGKDD international conference on Knowledge discovery and data mining, 2013, pp. 605-613. DOI:10.1145/2487575.2487576

[41] O. Järv, R. Ahas, and F. Witlox, "Understanding month ly variability in human activity spaces: A twelve-month study using mobile phone call detail records," Transp. Res. Part C Emerg. Technol., vol. 38, pp. 122-135, 2014. DOI:10.1016/j.trc.2013.11.003

[42] P. Bouman, E. van der Hurk, L. Kroon, T. Li, and P. Vervest, "Detecting activity patterns from smart card Data", in 25th Benelux Conference on Artificial Intelligence (BNAIC 2013), 2013. DOI:10.3141/2276-06

[43] M. Bagchi and P. R. White, "The potential of public transport smart card data," Transp. Policy, vol. 12, no. 5, pp. 464-474, 2005. DOI:10.1016/j.tranpol.2005.06.008

[44] E. Van der Hurk, L. Kroon, T. Li T, G. Maróti and P. Vervest, "Using Smart Card Data For Better Disruption Management In Public Transport: Predicting travel behavior of passengers", in 11th TRAIL Congress "Connecting people, Integrating expertise", pp. 1-5. 2010. [Online]. Available: http://rstrail.nl/new/wp-content/ uploads/2015/02/Hurk_0.pdf

[45] N. Lathia, C. Smith, J. Froehlich, and L. Capra, "Individuals among commuters: Building personalised transport information services from fare collection systems," Pervasive Mob. Comput., vol. 9, no. 5, pp. 643664, 2013. DOI:10.1016/j.pmcj.2012.10.007

[46] C. Morency, M. Trépanier, and B. Agard, "Measuring transit use variability with smart-card data," Transp. Policy, vol. 14, no. 3, pp. 193-203, 2007. DOI:10.1016/j. tranpol.2007.01.001

[47] M. Li, B. Du, and J. Huang, "Travel patterns analysis of urban residents using Automated Fare Collection System," in 12th International Conference on Telecommunications (ITST), pp. 442-446, 2012. DOI:10.1109/ ITST.2012.6425216

[48] L. Liu, A. Hou, A. Biderman, C. Ratti, and J. Chen, "Understanding individual and collective mobility patterns from smart card records: A case study in Shenzhen," in 12th International IEEE Conference on Intelligent Transportation Systems, pp. 1-6, 2009. DOI:10.1109/ ITSC.2009.5309662

[49] M. E. Sánchez, Integración de Foursquare y Geolocalización en una Aplicación Móvil para la Creación de Rutas Turísticas, 2012.

[50] M. Nanni, R. Trasarti, C. Renso, F. Giannotti, and D. Pedreschi. "Advanced knowledge discovery on movement data with the GeoPKDD system", in Proc. ACM EDBT '10, New York, USA, 2010, pp. 693-696. DOI: 10.1145/1739041.1739129
[51] Z. Yan, D. Chakraborty, C. Parent, S. Spaccapietra, and K. Aberer, "Semantic trajectories: Mobility data computation and annotation", ACM Trans. Intell. Syst. Technol. Vol. 4, no. 3, 2013. DOI:10.1145/2483669.2483682

[52] T. M. T. Do and D. Gatica-Perez, "The Places of Our Lives: Visiting Patterns and Automatic Labeling from Longitudinal Smartphone Data," IEEE Trans. Mob. Comput., vol. 13, no. 3, pp. 638-648, 2014. DOI:10.1109/ TMC.2013.19

[53] [53] F. Calabrese, M. Diao, G. Di Lorenzo, J. Ferreira, and C. Ratti, "Understanding individual mobility patterns from urban sensing data: A mobile phone trace example," Transp. Res. Part C Emerg. Technol., vol. 26, pp. 301-313, 2013. DOI:10.1016/j.trc.2012.09.009

[54] Y. Yuan, M. Raubal, and Y. Liu, "Correlating mobile phone usage and travel behavior - A case study of Harbin, China," Comput. Environ. Urban Syst., vol. 36, no. 2, pp. 118-130, 2012. DOI:10.1016/j.compenvurbsys.2011.07.003

[55] C. Kang, X. Ma, D. Tong, and Y. Liu, "Intra-urban human mobility patterns: An urban morphology perspective," Phys. A Stat. Mech. its Appl., vol. 391, no. 4, pp. 1702-1717, 2012. DOI:10.1016/j.physa.2011.11.005

[56] V. Pande, W. Elmannai, and K. Elleithy, "Mobile and Wi-Fi Geo location using Google Latitude," in World Congress on Computer and Information Technology (WCCIT), 2013, pp. 1-5. DOI:10.1109/WCCIT.2013.6618709

[57] M. Piorkowski, "Sampling Urban Mobility through Online Repositories of GPS Tracks Categories and Subject Descriptors," in Proc. ACM HotPlanet '09. New York, USA, 2009, pp. 1-6. [En línea]. Disponible en: http://infoscience.epfl.ch/record/138714/files/PiorkowskiHotPlanet09PAPER.pdf. DOI: 10.1145/1651428.1651430

[58] Wikipedia, "Geoetiquetado." [En línea]. Disponible en: http://es.wikipedia.org/wiki/Geoetiquetado.

[59] C. Zhang, L. Shou, K. Chen, G. Chen, and Y. Bei, "Evaluating geo-social influence in location-based social networks," in 21st ACM international conference on Information and knowledge management, 2012, pp. 1442-1451. DOI: $10.1145 / 2396761.2398450$

[60] A. Tarasov, F. Kling, and A. Pozdnoukhov. "Prediction of user location using the radiation model and social check-ins", 2nd ACM SIGKDD International Workshop on Urban Computing. New York, USA, 2013, pp. 7. [En línea]. Disponible en: http://www.cs.uic. edu/ urbcomp2013/papers/Paper\%2018_Alexey\%20 Tarasov.pdf DOI:10.1145/2505821.2505833

[61] M. Lin and W.-J. Hsu, "Mining GPS data for mobility patterns: A survey," Pervasive Mob. Comput., vol. 12, pp. 1-16, 2014. DOI:10.1016/j.pmcj.2013.06.005

[62] Wikipedia, "Minería de datos," 2014. [En línea]. Disponible en: http://es.wikipedia.org/wiki/Minería_de_datos.

[63] M. Servente, "Algoritmos TDIDT aplicados a la minería de datos inteligente," Universidad de Buenos Aires, 2002.

[64] A. Monreale, F. Pinelli, R. Trasarti, and F. Giannotti. "WhereNext: a location predictor on trajectory pattern mining”, in 15th ACM KDD '09. New York, USA, 2009, pp. 637-646. DOI: 10.1145/1557019.1557091

[65] J. Han, J.-G. Lee, H. Gonzalez, and X. Li, "Mining massive rfid, trajectory, and traffic data sets (tutorial)," in ACM KDD'08, 2008, pp. 38. DOI:10.1145/1401890.1551566

[66] F. Giannotti, M. Nanni and D. Pedreschi, "Efficient Mining of Temporally Annotated Sequences," in Proc. SDM'06, Pisa, Italy, 2006, pp. 346-357. [En línea]. Disponible en: http://siam.org/ meetings/sdm06/proceedings/032 giannottif.pdf DOI:10.1137/1.9781611972764.31

[67] V. Daniel, P. Marc and T. Marc. "Citizen as a Sensor: The Barcelona Urban Mobility Use-case," in Smart City Expo World Congress, Barcelona, España. 2012. [En línea]. Disponible en: http://marcpous.com/pdf/Paper_SmartCityExpo_2012.pdf 
[68] EuropaPress, "Santander, Málaga y Zaragoza participan en los primeros pilotos del proyecto I+D+i en Smart Cities Ciudad 2020,” 2014. [En línea]. Disponible en: http:// noticias.lainformacion.com/economia-negocios-y-finanzas/software/santander-malaga-y-zaragoza-participanen-los-primeros-pilotos-del-proyecto-i-d-i-en-smart-cities-ciudad-2020_Kq1LUgkzBGGEHSM1Raue83/.

[69] Siemens, S. A. "Soluciones inteligentes para el tráfico de hoy y del mañana," Siemens Traffic Solutions, Madrid, pp. 1-14. 2013. [En línea]. Disponible en: https://www. swe.siemens.com/spain/web/es/industry/mobility/Documents/traffic.pdf

[70] Roadtraffic-Technology, "Hong Kong Intelligent Transport System (ITS), China,” 2014. [En línea]. Disponible en: http://www.roadtraffic-technology.com/projects/hongkong/

[71] Alcaldía de Medellín, “Qué es el SIMM?” 2014. [En línea]. Disponible en: http://www.medellin.gov.co/SIMM/.

[72] H. Lin, "Applying location based services and social network services onto tour recording" in International Joint Conference on Computer Science and Software Engineering (JCSSE),2012, pp. 197-200. DOI:10.1109/JCSSE.2012.6261951

[73] Y. Yang, B. Du, and X. Jiang, "A Human Trajectory Estimate Based on Individual Mobility Pattern Library," IEEE International Conference on Green Computing and Communications and IEEE Cyber, Physical and Social Computing (GreenCom), IEEE and Internet of Things (iThings/CPSCom), pp. 1181-1185, 2013. DOI:10.1109/ GreenCom-iThings-CPSCom.2013.205

[74] N. Lathia, J. Froehlich, and L. Capra, "Mining Public Transport Usage for Personalised Intelligent Transport Systems," IEEE 10th International Conference on Data Mining (ICDM), pp. 887-892, 2010. DOI:10.1109/ ICDM.2010.46
[75] L. Tang and P. (Vonu) Thakuriah, "Ridership effects of real-time bus information system: A case study in the City of Chicago," Transp. Res. Part C Emerg. Technol., vol. 22, pp. 146-161, 2012. DOI:10.1016/j. trc.2012.01.001

[76] L. Wu-Hs, "Loco-Radio - Designing High-Density Augmented Reality", Ph.D. dissertation, School of Architecture and Planning, Massachusetts Institute of Technology, Massachusetts, 2014. [En línea]. Disponible en: http://web.media.mit.edu/ wuhsi/download/li_wuhsi_ phd thesis_final.pdf

[77] G. Pestana, A. Casaca, I. Rebelo, S. Couronné, and I. Ist, "LocON : A Location Based Services Platform to Improve Airport Safety," IEEE Aerospace Conference, 2011, vol., no., pp.1, 10, 5-12, 2011. DOI:10.1109/ AERO.2011.5747375

[78] M.R. Ebling, and R. Cáceres, "Gaming and Augmented Reality Come to Location-Based Services," IEEE Computer Society, vol. 9, pp. 5-6, 2010. DOI:10.1109/ MPRV.2010.5

[79] PresseLite, (2014, Jun) "L’application Métro Paris sur iPhone et iPod Touch" 2014. [En línea]. Disponible en: http://www.presselite.com/iphone/metroparis/

[80] J. Gubbi, R. Buyya, S. Marusic, and M. Palaniswami. "Internet of Things (IoT): A vision, architectural elements, and future directions". Future Gener. Comput. Syst. vol. 29, no. 7, pp. 1645-1660, 2013. DOI:10.1016/j. future.2013.01.010

[81] H. Chenji, W. Zhang; M. Won, R. Stoleru and C Arnett, C., "A wireless system for reducing response time in Urban Search \& Rescue," IEEE 31st International Performance Computing and Communications Conference, vol., no., pp.215, 224, 2012. DOI:10.1109/ PCCC.2012.6407756 